\title{
A aplicação do princípio da solidariedade na judicialização da saúde a partir dos princípios do SUS, da fixação de entendimento pelo STF e da trajetória do Rio Grande do Sul
}

The application of the principle of solidarity in the judicialization of health based on the principles of SUS, the establishment of understanding by the Supreme Court and the trajectory of Rio Grande do Sul, Brazil

La aplicación del principio de solidaridad en la judicialización de la salud basada en los principios del SUS, el establecimiento del entendimiento por parte de la Corte Suprema y la trayectoria de Rio Grande do Sul, Brazil

Patricia De Carli ${ }^{1}$

Bruno Naundorf ${ }^{2}$

\section{Resumo}

Objetivo: analisar o fenômeno da judicialização da saúde e a temática da solidariedade entre os entes federados a partir dos princípios da integralidade e da universalidade que orientam o Sistema Único de Saúde (SUS), bem como do recente posicionamento do Superior Tribunal Federal (STF) a partir da trajetória da judicialização no Estado do Rio Grande do Sul. Métodos: realizou-se levantamento bibliográfico e análise de dados coletados junto ao Sistema de Administração de Medicamentos da Secretaria de Saúde do Estado do Rio Grande do Sul. Resultados: a reiterada adoção da tese de solidariedade entre os entes pelos tribunais nas ações de saúde acaba por vulnerar o SUS, na medida em que não observa os princípios de organização e financiamento da política pública de saúde. Conclusão: a despeito do novo posicionamento do STF significar um avanço, no sentido de que a obrigação é solidária entre os entes, mas compete à autoridade judicial direcionar o cumprimento conforme as regras de repartição de competências, bem como o ressarcimento a quem suportou o ônus financeiro, muitas dúvidas de ordem processual ainda se impõe, sendo que a observância dos princípios de organização e financiamento do SUS são fundamentais para que se possa garantir a existência de um Sistema universal.

Palavras-chave: Judicialização da saúde. Integralidade em saúde. Sistema Único de Saúde. Poder Judiciário.

\footnotetext{
Abstract

Objective: to analyze the phenomenon of judicialization of health and the theme of solidarity among federated entities from the principles of comprehensiveness and universality that guide the Unified Health System (SUS), as well as the recent position of the Federal Superior

${ }^{1}$ Graduada em Direito pela UPF; especialista em Gestão Pública pela UFSM; mestre em Direito pela UNISC; doutoranda em Desenvolvimento Regional pela Unijuí; Assessora Jurídica da Secretaria de Saúde do Estado do Rio Grande do SulSES/RS. E-mail: E-mail: patricia-decarli@saude.rs.gov.br

2 Bacharel em Direito (PUCRS); especialização em Direito de Estado (UFRGS) e em Direito Sanitário (ESP/RS e Unisinos), mestrando em Ensino na Saúde (UFRGS); diretor do Departamento de Auditoria do SUS/RS. E-mail: bnaundorf@gmail.com
} 
Court (STF) based on the path of judicialization in the State of Rio Grande do Sul, Brazil. Methods: a bibliographic survey and analysis of data collected from the Drug Administration System of the Health Secretariat of the State of Rio Grande do Sul were performed. Results: the repeated adoption the thesis of solidarity between the courts by the courts in health actions ends up undermining the SUS, insofar as it does not observe the principles of organization and financing of public health policy. Conclusion: despite the new position of the Supreme Court means an advance, in the sense that the obligation is solidary among the entities, but it is up to the judicial authority to direct compliance with the rules of division of powers, as well as compensation to those who bore the burden. financial, many procedural doubts remain, and the observance of the principles of organization and financing of the SUS are fundamental to ensure the existence of a universal system.

Keywords: Health's judicialization. Integrality in health. Unified Health System. Judiciary.

\section{Resumen}

Objetivo: analizar el fenómeno de la judicialización de la salud y el tema de la solidaridad entre las entidades federadas a partir de los principios de integralidad y universalidad que guían al SUS, así como el reciente posicionamiento del STF en el camino de la judicialización en el estado de Rio Grande do Sul, Brasil. Métodos: se realizó una encuesta bibliográfica y un análisis de los datos recopilados del Sistema de Administración de Medicinas de la Secretaría de Salud del Estado de Rio Grande do Sul. Resultados: finaliza la adopción reiterada de la tesis de solidaridad entre los tribunales en acciones de salud por violar el Sistema Único de Salud, ya que no observa los principios de organización y financiamiento de la política de salud pública. Conclusión: a pesar de la nueva posición de la Corte Suprema, en el sentido de que la obligación es conjunta y solidaria, pero corresponde a la autoridad judicial dirigir el cumplimiento de las reglas de división de poderes, así como la compensación a quienes soportan la carga financiera, significa Un avance, todavía quedan muchas dudas de procedimiento, y la observancia de los principios de organización y financiación del SUS son fundamentales para garantizar la existencia de un sistema universal.

Palabras clave: Judicialización de la salud. Integralidad en salud. Sistema Único de Salud. Poder Judicial.

\section{Introdução}

A judicialização da saúde tem sido tema recorrente no âmbito da gestão pública, da academia e dos tribunais. Aspectos como a garantia de direitos, o fortalecimento do Sistema Único de Saúde (SUS), a realocação de recursos e os impactos orçamentários têm sido ponderados nesse debate. (1)

Diante da pertinência e atualidade do assunto, o presente artigo tem por objetivo analisar a judicialização da saúde e o impacto desta no SUS, usando como referência a ocorrida no Estado do Rio Grande do Sul, e discorrer acerca da temática da solidariedade entre os entes federados a partir dos princípios da integralidade e da universalidade que 
orientam o SUS, bem como debater o recente posicionamento do Supremo Tribunal Federal (STF) sobre a matéria.

O artigo foi construído a partir de levantamento bibliográfico e análise de dados coletados junto ao Sistema de Administração de Medicamentos da Secretaria de Saúde do Estado do Rio Grande do Sul e abordará: a) a judicialização da saúde e o impacto no Estado do Rio Grande do Sul; b) o sentido constitucional do princípio da integralidade e; c) a relação da exata compreensão da solidariedade entre os entes e a universalidade do SUS.

\section{Metodologia}

Para este estudo, inicialmente foi realizada uma pesquisa bibliográfica, com coleta de dados realizada a partir de fontes secundárias.

Em um segundo momento, foram coletados e analisados dados disponíveis no Sistema de Administração de Medicamentos (AME) da Secretaria de Saúde do Estado do Rio Grande do Sul.

Criado no ano de 2005 com a finalidade de auxiliar na gestão e planejamento da Assistência Farmacêutica estadual, o AME funciona como um grande banco de dados, que armazena as informações de cadastro, tratamento, dispensações de medicamentos, rastreamento, posição de estoque, lote, validade, emissão de recibos e valores dos tratamentos.

Trata-se de um sistema com diferentes níveis de acesso de acordo com o perfil do usuário, compartilhado por operadores da Gestão de Saúde estadual, municipal e sistema de Justiça.

Para fins de análise neste trabalho, utilizou-se relatório com dados genéricos do quantitativo geral da demanda estadual, relativo ao período de 2005 a julho 2019, quando foi realizado o levantamento.

\section{A judicialização da saúde e o impacto no Estado do Rio Grande do Sul}

Os estudos sobre judicialização da saúde têm aumentado a cada ano, demonstrando a importância do tema e buscando meios de compreender e apontar soluções para o problema. Embora o tema saúde como um direito não seja um objeto de estudo recente no Brasil, haja vista a larga produção do conhecimento no campo da saúde coletiva, os estudos 
e as pesquisas sobre o tema do direito à saúde carecem de um aporte de reflexões acadêmicas que possam dar o suporte teórico e delimitar os marcos jurídico-legais da saúde como um campo de práticas sociais. (2)

A judicialização consiste no resultado de um processo histórico, típico do constitucionalismo democrático, que tem por base múltiplos fatores, mas, principalmente na Constituição, em especial na dimensão objetiva dos direitos fundamentais. (3)

$\mathrm{Na}$ última década, não apenas na área da saúde, a transferência de decisões estratégicas sobre temas fundamentais ao Poder Judiciário foi gradativa, os quais, antes, estavam tradicionalmente reservados à esfera política e deliberativa. Desenhou-se uma forte mudança nas políticas públicas como as relacionadas à incorporação de tecnologia no SUS e o acesso aos serviços públicos ofertados por este, fazendo com que o direito à saúde seja, cada vez mais, um direito judicial construído, no caso concreto, pelos magistrados e demais atores envolvidos no que se denomina judicialização da saúde. (4)

Nesse aspecto, o Estado do Rio Grande do Sul foi o pioneiro na judicialização da saúde de massa no Brasil, que remonta ao princípio dos anos 2000. (5)

Esse fenômeno revelou que, embora justificado no direito constitucional à saúde, a lógica presente nos tribunais passou a reforçar um fator bastante presente na história da saúde pública brasileira e da formação das políticas públicas de saúde, mediante uma dicotomia entre saúde coletiva e saúde individual, baseada em uma concepção de ser o SUS o responsável apenas pela organização de ações de recuperação da saúde do indivíduo, mas deixando de lado a necessidade de compreensão da amplitude e da relevância das políticas de cunho coletivo, de proteção e prevenção. (6)

A Constituição de 1988 optou por um modelo de atenção universal e coletivo, e conforme os dizeres do artigo 196, mediante políticas sociais e econômicas que visem à redução do risco de doença e de outros agravos e ao acesso universal e igualitário às ações e serviços para sua promoção, proteção e recuperação.

No entanto, a judicialização da saúde passou a privilegiar o direito individual daqueles que alcançam o sistema judiciário, muitas vezes em detrimento do coletivo e desconsiderando o caráter coletivo do sistema. $O$ fato é que, ao deferir qualquer insumo de saúde não incorporado ao sistema público, estar-se-á privilegiando um indivíduo em detrimento de todos aqueles que estejam na exata situação deste, ferindo os princípios 
norteadores do SUS, em especial o princípio da universalidade.

Conforme demonstram os dados de controle interno da Secretaria de Estado da Saúde do Rio Grande do Sul (SES/RS), coletados no AME, analisando o quantitativo de processos ativos com deferimento de entrega por ordem judicial para o Estado do RS, em julho de 2019, há um quantitativo de tratamentos já incorporados ao SUS: 9\% relativo a medicamentos básicos, de responsabilidade dos municípios; $20,6 \%$ vinculado ao componente especializado definido pela União; 5,5\% do componente estadual (medicamentos especiais); e um pequeno quantitativo de medicamentos estratégicos $(0,6 \%)$, de competência exclusiva da União. (7)

Verifica-se que a maior parte da demanda judicial $(64,3 \%)$ se refere a medicamentos classificados como fora de quaisquer listas de fornecimento do SUS. Importante aqui levantar que, conforme dados de 2017, extraídos do mesmo sistema de informação, esse quantitativo de medicamentos não incorporados tem crescido nos últimos anos, passando de $58,3 \%$ para os atuais 64,3 . Tal fato gera preocupação com a não observância, pelo Poder Judiciário, do disposto na Lei no 8.080/90, que define que

(...) na falta de protocolo clínico ou de diretriz terapêutica, a dispensação será realizada com base nas relações de medicamentos instituídas pelo gestor federal do SUS, observadas as competências estabelecidas nesta Lei, e a responsabilidade pelo fornecimento será pactuada na Comissão Intergestores Tripartite. (8)

Assim, a não observância desse importante aspecto definido pelo legislador tem gerado a desorganização do sistema.

Importa destacar que tem sido apresentado números preocupantes do volume de recursos direcionados para o atendimento de ordens judiciais na área de saúde em todas as esferas de gestão, e, em especial, pelo Estado do Rio Grande do Sul, que chegou à ordem de $16 \%$ de toda a execução orçamentária da SES/RS, segundo dados internos do Fundo Estadual de Saúde, equivalente a $\mathrm{R} \$ 436$ milhões de reais, considerando os recursos liquidados em 2018. (9)

Apesar de a saúde pública acolher e disponibilizar tratamentos e instrumentos terapêuticos de forma individualizada, tendo por norte uma atuação que respeita a individualidade, as vivências, escolhas e ciclo de vida de cada usuário é preciso considerar que a base de organização e planejamento da política pública de saúde deve partir de um 
viés de saúde coletiva, privilegiando a promoção e proteção da saúde, essência do movimento da reforma sanitária e da própria Constituição.

Em solo gaúcho, a judicialização da saúde em massa teve seu primórdio no ano de 1998, com a busca pelo acesso a tratamentos contra o vírus HIV, tendo evoluído paulatinamente. A partir de 2003, houve um salto significativo no ingresso de novas ações judiciais, aumentando de maneira expressiva nos anos seguintes, tendo seu ápice nos anos de 2013 e 2014 (5), estando ainda o Estado do Rio Grande do Sul com elevado índice de demandas judiciais de saúde. Conforme dados internos da Assistência Farmacêutica da SES/RS, o panorama atual demonstra que, para além dos medicamentos constantes da lista de atribuição do Estado, são disponibilizados ainda 5.265 tipos distintos de apresentações de medicamentos, para a população por determinação judicial. (10)

Dessa breve contextualização, vê-se que o fenômeno da judicialização se desenvolveu no Estado do Rio Grande do Sul, tendo por característica o excessivo número de demandas e um atendimento que privilegia o direito individual frente ao direito coletivo previsto pelo SUS.

Criou-se uma face perversa ao destinar um alto valor para um número reduzido de pacientes e tornar dificultoso $o$ atendimento eficaz daqueles pacientes aptos a obterem os medicamentos pelo SUS. Também se impediu a possibilidade de ampliação dos tratamentos previstos, uma vez que os recursos destinados à saúde são finitos e únicos, razão pela qual se faz imperioso avaliar quais são os impactos da judicialização da saúde na gestão pública.

A despeito do posicionamento dos autores, não se pode olvidar que a judicialização também decorre de outros fenômenos como a desorganização de estoques e a necessidade de organização de fluxos administrativos, conforme já debatido em publicações anteriores $(11,5)$.

A judicialização em massa, quando carente de critérios técnicos, em especial sobre o funcionamento do sistema público de saúde, pode gerar a desorganização do SUS. Quando há o enfrentamento jurídico necessário para a tomada de decisões pelos operadores do direito, muitas vezes estes carecem de informações suficientes, eis que não há, praticamente, o ensino do direito sanitário no ensino regular da área jurídica. Falta, geralmente, aos operadores de direito, preparo adequado para a resolução de casos atendendo na íntegra aos princípios e diretrizes do SUS. 
Entretanto, importa referir que inúmeras iniciativas vêm sendo desenvolvidas de forma conjunta entre o sistema da saúde e o sistema da Justiça no intento de se alcançar o melhor resultado para a política pública de saúde e o cidadão que pleiteia o seu direito em juízo. Algumas dessas iniciativas são apresentadas pelos autores Naundorf, Carli e Goulart. (5)

A lei constitucional garante ao cidadão ingressar com ação judicial, de forma individual ou coletiva (3), quando não obter acesso a bens ou serviços de saúde indicados ou mais adequados ao seu estado de saúde, conforme preceitua seu médico eleito, pertencente ou não ao sistema público de saúde. Isso, porém, não significa um deferimento geral e irrestrito, pois a Constituição precisa ser analisada nos limites da dicção do artigo 196, que privilegia a saúde como um direito coletivo, garantido mediante políticas públicas a serem instituídas pelo gestor. (12)

A judicialização da saúde é entendida como uma questão ampla na busca de bens e direitos nas Cortes: são insumos, instalações, medicamentos, assistência em saúde, entre outras demandas a serem buscadas ao abrigo do princípio do direito à saúde. (13)

A origem da judicialização é ainda incerta, não apenas pela ausência de estudos empíricos sistemáticos e comparativos no país, mas principalmente pela amplitude da judicialização e seus diferentes níveis de expressão nas Cortes. Há possibilidade de a efetivação do direito gerar uma interferência indevida do Judiciário nas políticas públicas caso a decisão judicial não adote critérios objetivos e uniformes, ou não seja munida de informações suficientes para uma correta avaliação quanto à viabilidade e adequação técnica e orçamentária do bem demandado. (13)

As demandas judiciais não podem ser consideradas como principal instrumento deliberativo na gestão do SUS, porém não se pode olvidar que elas são admitidas como um elemento importante na tomada de decisão dos gestores. Atuam, muitas vezes, na melhoria do acesso aos medicamentos no âmbito do SUS, podendo expressar reivindicações e modos de atuação legítimos de cidadãos e de instituições, além de auxiliar na formulação de estratégias políticas e sociais que aperfeiçoem os sistemas de saúde e de justiça com vistas à efetividade do direito à saúde. (2)

No debate sobre a judicialização, há necessidade de dedicar mais atenção às análises econômicas e à medicina baseada em evidências, mas a judicialização pode, por si só, ajudar a criar uma fonte alternativa de informação denominada evidência baseada na prática. 
Isso porque as evidências baseadas na prática apontam para onde os mecanismos administrativos existentes falham e oferecem pistas sobre como melhorar a gestão da saúde pública. Conforme abordam Biehl, Socal e Amon (14), embora muitas vezes descartadas como tais, as demandas individuais não são simplesmente a antítese da necessidade coletiva porque experiências individuais são moldadas por fenômenos comuns dentro de diferentes comunidades.

Na análise das políticas de saúde no Brasil de hoje, não se pode ignorar os artigos 6º e 196 da Constituição Federal de 1988, que reconhecem a saúde como direito fundamental das pessoas e dever do Estado, fazendo com que o que antes era analisado apenas sob aspecto técnico e político passasse a ser também jurídico e de ordem constitucional. As implicações dessa juridicização constitucional das políticas de saúde estão longe de ser triviais, impondo aos técnicos em saúde pública princípios e limites legais que antes não estavam presentes ou, quando estavam, não se revestiam da força de normas constitucionais. (13)

Compreende-se atualmente que a chamada judicialização da saúde somente trará efeitos positivos se auxiliar na ordenação do sistema e na imposição de cumprimento daquilo que está prometido no âmbito constitucional e nas políticas públicas previstas na legislação infraconstitucional, ou seja, atuando na tutela coletiva das políticas públicas já existentes e na busca por avanços. A distribuição desordenada de benefícios, além de atingir um número muito pequeno de beneficiários, vulnera as políticas existentes em favor da coletividade. (15)

A judicialização da saúde impacta de forma significativa a gestão pública, na medida em que interfere diretamente nas rotinas administrativas de gestão de recursos humanos e financeiros da secretaria da saúde. Também impõe aos entes federativos o fornecimento de tratamentos fora das suas listas de competência e da legalidade a que se vincula à Administração Pública, desprezando as diretrizes, organização e princípios que orientam o SUS e vulnerando, assim, a sua futura existência. (5)

\section{O sentido constitucional do princípio da integralidade}

O atendimento integral, com prioridade para as atividades preventivas, sem prejuízo dos serviços assistenciais, é uma das diretrizes do SUS, dispostas no artigo 198 da Constituição Federal de 1988. (12) 
A Lei no 8.080/90, que dispõe sobre as condições para a promoção, proteção e recuperação da saúde, a organização e o funcionamento dos serviços correspondentes, abordou a temática, em seu artigo $7^{\circ}$, determinando que o sistema deve obedecer ao princípio da integridade, entendida como um "conjunto articulado e contínuo das ações e serviços preventivos e curativos, individuais e coletivos, exigidos para cada caso em todos os níveis de complexidade do sistema". (8)

É possível perceber que o princípio da integralidade é desafiador no que se refere a sua construção conceitual, uma vez que diz respeito diretamente à forma de organização dos serviços, englobando saberes de profissionais, usuários e comunidade, em busca por mesclar, nos planos da gestão e da assistência, tanto a qualidade técnica do trabalho, quanto o sentido político dos direitos de cidadania. (16)

Nessa perspectiva de organização do sistema, a integralidade é elemento fundamental para que se possa garantir os demais princípios do SUS: a universalidade e a equidade da atenção à saúde. Entretanto, por ser um processo em constante construção, pautado no diálogo, pactuação e cooperação entre entes federados, e contemplando múltiplos sujeitos, instituições e práticas, por vezes gera dificuldade de compreensão e conceituação. (16)

A integralidade surge como princípio do SUS na Constituição de 1988, entretanto, fundamentos semelhantes vêm sendo debatidos em âmbito acadêmico desde a década de 1950, pautadas em duas noções fundamentais trazidas dos Estados Unidos: integração de serviços e atenção integral. Essa composição de termos engloba tanto o entendimento do ser humano como um todo biopsicossocial - em contraposição à intensa especialização da prática médica -, como a necessária integração e articulação das ações de promoção, prevenção, tratamento e reabilitação, do ponto de vista da organização da atenção à saúde. $(16,17)$

O vínculo entre as três dimensões do direito à saúde corresponde, portanto, a concretude do princípio da equidade. Essas dimensões são a gestão do cuidado individual; a gestão dos serviços em que esse cuidado é produzido; e a gestão sistêmica das redes de atenção à saúde. $(16,17)$ O viés constitucional apresenta a integralidade pensada na lógica do acesso e articulação de todas as ações e níveis de atenção à saúde, e assim precisa ser compreendida pelo Poder Judiciário. (17) 
A integralidade da atenção se dá em duas dimensões: focalizada e ampliada. A primeira representa o compromisso de promover a melhor escuta das necessidades de saúde trazidas pela população por uma equipe ou um serviço determinado. A despeito da relevância dessa dimensão, ela por si só não garante a efetivação plena do princípio da integralidade, razão pela qual é necessário existir também a dimensão ampliada, que corresponde a articulação entre os serviços de saúde e seus diversos graus de complexidade e densidade tecnológica. (18)

Em um país de dimensão continental como o Brasil, caracterizado por heterogeneidades estruturais de ordem produtiva, social, epidemiológica e regional, (19) a organização de um sistema universal de saúde perpassa por um necessário processo de descentralização, regionalização e municipalização do SUS, o que implica na pactuação entre as três esferas de governo e em uma repartição de competências que assegure o preconizado pelo princípio da integralidade.

Diante dessa necessidade de organização dos serviços, a concepção de redes de atenção à saúde (RAS) vem sendo discutida há algum tempo no Brasil, entretanto, passou a ter existência jurídica recentemente, compondo o arcabouço normativo do SUS por meio da Portaria de Consolidação no 03, de 28 de setembro de 2017, que estabelece no seu Anexo I as diretrizes para a organização das redes de atenção à saúde no SUS, e do Decreto no 7.508, de 28 de junho de 2011, que regulamenta a Lei no 8.080/1990. $(20,21,8)$

As RAS consistem em arranjos organizativos de ações e serviços de saúde, de diferentes densidades tecnológicas, que integradas por meio de sistemas de apoio técnico, logístico e de gestão, buscam garantir a integralidade do cuidado (22).

Podem ser vistas como um conjunto de serviços de saúde, interligados por objetivos comuns e por uma ação cooperativa e interdependente, que permite ofertar uma atenção contínua e integral a determinada população e coordenada pela atenção primária em saúde: prestada no tempo certo, no lugar certo, com o custo certo, com a qualidade certa, de forma humanizada e segura e com equidade, com responsabilidades sanitária e econômica pela população adscrita, gerando valor para essa população (23).

Importa referir que nesse modelo de organização todos os componentes da rede são igualmente importantes, diferenciando-se apenas pelas respectivas densidades tecnológicas que os caracterizam. O modelo se torna viável a partir da aplicabilidade de três 
princípios expressos no artigo $7^{\circ}$ da Lei ํㅡㅇ 8.080/90:

XI - conjugação dos recursos financeiros, tecnológicos, materiais e humanos da União, dos Estados, do Distrito Federal e dos Municípios na prestação de serviços de assistência à saúde da população;

XII - capacidade de resolução dos serviços em todos os níveis de assistência; e

XIII - organização dos serviços públicos de modo a evitar duplicidade de meios para fins idênticos. (8)

Conforme identifica Mendes (23), os fundamentos da organização do SUS a partir das RAS podem ser expressos nos valores a seguir: economia de escala; suficiência e qualidade; acesso; disponibilidade de recursos; integração vertical; e integração horizontal.

Conclui-se que o SUS é definido constitucionalmente como o resultado da integração das ações e serviços públicos de saúde, em rede regionalizada e hierarquizada, cabendo a todos os entes federativos dar efetividade ao direito social à saúde. (24)

Diante do conceito de integralidade, que exige um conjunto interligado e complexo de ações de promoção, prevenção e recuperação, não há como um único ente realizar sozinho todas as prestações que esse direito envolve. Sobretudo, em um contexto territorial de inequidades de toda ordem. (24) Esse modelo gera, ao mesmo tempo, a descentralização das ações e serviços de saúde - em observância ao modelo federativo e de competência tripartite da saúde - e a aglutinação das autonomias federativas em cada região de saúde, em virtude da integralidade. (24)

Como a Constituição Federal não determinou de forma expressa o que incumbiria a cada ente, cabe às instâncias de pactuação intergestores decidir sobre os aspectos operacionais, financeiros e administrativos da gestão compartilhada do SUS, nos termos do artigo 14-A da Lei oㅜ 8.080/90. Em conformidade com a política consubstanciada em planos de saúde, define-se diretrizes para: a organização das redes de ações e serviços de saúde; as regiões de saúde, distritos sanitários, integração de territórios; a referência e contrareferência e demais aspectos relativos à integração das ações e serviços de saúde entre os entes federados. Esse esforço de organização sistêmica acabou, ao longo da história do SUS, por gerar dificuldades de compreensão de toda a ordem. $(24,25)$

Talvez em razão da complexa e intrincada organização do SUS, inúmeras decisões judiciais são proferidas contra entes federativos com fulcro no princípio da solidariedade. Em tempos de judicialização de massa, compreender a solidariedade entre os entes a partir de 
um conceito de universalidade no acesso se torna condição de possibilidade para que se possa garantir, não apenas o fortalecimento, mas a própria existência do SUS. Conforme será debatido no próximo tópico, a tese fixada pelo STF por ocasião do julgamento do Recurso Extraordinário oㅜ 855178 abre espaço para o debate sobre esses temas.

\section{À guisa de conclusão: qual é a relação entre a exata compreensão da solidariedade entre os entes e a universalidade do SUS?}

O princípio da solidariedade, assim como da dignidade humana, presentes respectivamente nos artigos $3^{\circ}$ e $1^{\circ}$, compõe a base nuclear principiológica da Constituição Federal de 1988. Entretanto, a fim de que o Estado brasileiro possa, de fato, cumprir com os direitos sociais previstos no texto legal, algumas fórmulas jurídicas e de gestão foram pensadas.

No direito à saúde, em específico, a organização tripartite de ações, políticas, programas e financiamento foi desenhada entre os entes federados de forma que cada um possa contribuir de acordo com as demandas mais prevalentes e capacidade financeira de cada escala, tudo de acordo com as prioridades pactuadas nas instâncias de gestão espaços democráticos de amplo debate e que são a forma organizativa do sistema. (25)

A solidariedade, enquanto norte constitucional e de organização do Estado e de suas políticas públicas, refere-se a um sentido de cooperação mútua entre pessoas ou entes; identidade; interdependência de sentimentos e ideias. (26) Distingue-se, portanto, do conceito jurídico de obrigações solidárias, disposto no artigo 264 do Código Civil Brasileiro, que se refere à concorrência de mais de um devedor ou obrigado à determinada prestação, que não pode (e não deve) ser utilizado no âmbito da saúde, sob pena da total desorganização do SUS. (27)

A solidariedade não pode ser orientada de forma a qualquer pleito que se julgue como uma necessidade de saúde possa ser endereçado indiscriminadamente para qualquer ente, pois tal fórmula impacta fortemente na (des)organização dos serviços de saúde, limitando as políticas de alcance coletivo; priorizando a tutela individual; e, principalmente, desvirtuando a essência filosófica da igualdade que justifica a própria existência dos direitos sociais. 
Ao longo dos anos, o princípio da solidariedade de garantia do direito à saúde tem sido invocado recorrentemente pelo Poder Judiciário. Em quase todas as decisões proferidas desde o início da judicialização, esse princípio foi utilizado para impor as mesmas responsabilidades, de forma indiscriminada, em relação ao direito à saúde a todos os entes federativos, sem considerar suas diferenças demográficas, econômicas, sociais, culturais. (28)

A título exemplificativo, mesmo que um município tenha apenas cinco mil habitantes e sua renda advir quase que totalmente do fundo de participação dos municípios, as responsabilidades imputadas a ele poderiam ser do mesmo grau às que se impõe à União. (28)

Nessa esteira, os municípios, de modo especial, passaram a se organizar em instituições e abrir o campo de debate, demonstrando que, em muitos casos, uma condenação judicial para atendimento de um paciente individual poderia consumir 0 orçamento de uma coletividade inteira.

O debate também ganhou corpo em nível estadual. Dentre os argumentos, apresentava-se uma compreensão da solidariedade a partir do princípio da integralidade, em uma leitura, como acima exposto, de um sistema organizado a partir da conjugação das ações e serviços de todos os entes federativos em uma região de saúde, integrados em redes de atenção à saúde. A solidariedade, portanto, ínsita ao SUS, é a que advém da hierarquização do nível de complexidade de serviços. (28)

Essa forma organizativa busca garantir a equidade nas relações federativas e o acesso universal. $\mathrm{O}$ ente com maior poder econômico deverá solidarizar-se com o ente de menor poder econômico e garantir, ao cidadão residente naquele território, serviços de maior complexidade ou densidade tecnológica diante da incapacidade econômico-financeira, da falta de escala e estrutura administrativa para a criação de serviços mais complexos. (28)

Conclui-se que a solidariedade deve se dar no sistema, na rede de atenção à saúde, e não entre entes, no sentido de todos terem, igualmente, de garantir os mesmos direitos a todo e qualquer cidadão. (28)

Esse debate, sempre presente na pauta dos estudos acerca da judicialização, fundamentou, em 2009, a Audiência Pública no 09 no STF. (29) Entretanto, muitas decisões judiciais mantiveram o entendimento no sentido de que o polo passivo poderia ser composto 
por qualquer ente, de forma conjunta ou isolada.

Em 2019, com a apreciação aos embargos de declaração propostos no Recurso Extraordinário o 855178 , foi fixada a tese de repercussão geral, que determinou expressamente que, a despeito do entendimento de que a obrigação é solidária entre os entes, compete à autoridade judicial direcionar o cumprimento conforme as regras de repartição de competências; e determinar o ressarcimento a quem suportou o ônus financeiro. $(30,31)$.

A decisão restou assim consignada:

Decisão: Preliminarmente, votou o Ministro Celso de Mello acompanhando o Ministro Edson Fachin na rejeição dos embargos de declaração. $\mathrm{Na}$ sequência, o Tribunal, por maioria, fixou a seguinte tese de repercussão geral (Tema 793): "Os entes da federação, em decorrência da competência comum, são solidariamente responsáveis nas demandas prestacionais na área da saúde, e diante dos critérios constitucionais de descentralização e hierarquização, compete à autoridade judicial direcionar o cumprimento conforme as regras de repartição de competências e determinar o ressarcimento a quem suportou o ônus financeiro," nos termos do voto do Ministro Edson Fachin, Redator para o acórdão, vencido o Ministro Marco Aurélio, que não fixava tese. Presidência do Ministro Dias Toffoli. Plenário, 23.05.2019. (30, grifos dos autores)

O dever imputado à autoridade judicial de direcionar o cumprimento conforme as regras de repartição de competências, embora represente um avanço em termos de entendimento, acaba por suscitar dúvidas de ordem processual, tais como:

a) como cumprir o determinado quando o ente não faz parte do processo? b) a decisão obriga a formação de litisconsórcio passivo necessário?

c) como incluir outro ente no polo passivo?

d) caberá ao ente demando requerer ou o magistrado deverá fazê-lo de ofício?

e) como ocorrerá a determinação de ressarcimento entre os entes?

A fim de tentar responder parcialmente a essas perguntas, importante referir que, no decorrer da discussão no plenário da Suprema Corte, embora ainda não se tenha acesso ao voto final, pois ainda não publicado, afirmou-se que

\footnotetext{
"se o ente legalmente responsável pelo financiamento da obrigação principal não compuser o polo passivo da relação jurídica processual, sua inclusão deverá ser levada a efeito pelo julgador, ainda que isso signifique deslocamento de competência". (31)
} 
O voto do Ministro Luiz Edson Fachin esclarece que:

se a pretensão veicular pedido de tratamento, procedimento, material ou medicamento não incluído nas políticas públicas em todas as suas hipóteses, a União necessariamente comporá o polo passivo, considerado que o Ministério da Saúde detém competência para incorporação, exclusão ou alteração de novos medicamentos, produtos, procedimentos, bem como constituição ou alteração de protocolo clínico ou de diretriz terapêutica, de modo que recai sobre ela o dever de indicar o motivo ou as razões da não padronização e eventualmente iniciar o procedimento de análise de inclusão nos termos da respectiva fundamentação. (31, grifos dos autores)

Da leitura das razões do voto, depreende-se que se privilegiou o enunciado 78 , do comitê executivo do Fórum de Saúde do Conselho Nacional de Justiça, que dispõe que "Compete à Justiça Federal julgar as demandas em que são postuladas novas tecnologias de alta complexidade ainda não incorporadas ao Sistema Único de Saúde - SUS". (32)

Em termos de políticas públicas, dividir responsabilidades - conforme preconizado na sua normativa de regência - significa somar esforços para que se possa garantir a existência de um sistema que contemple a garantia de acesso universal e igualitário às ações e serviços para sua promoção, proteção e recuperação, nos exatos termos do artigo 196 da Constituição Federal.

Destarte, "a crescente demanda por ações e serviços de saúde acessíveis e de qualidade impõe ao Estado a tomada de decisões políticas acertadas e que não esgarcem o já corroído tecido social" (33), ainda que a gestão pública seja alvo de críticas de institucionalização e exequibilidade, urgindo para que os princípios do SUS sejam observados em sua exata dicção por todos, sob pena de que o sistema universal padeça antes mesmo de vermos a consolidação do SUS, pensado pelo legislador Constituinte em 1988 e até hoje ainda não alcançado.

\section{Considerações finais}

A partir da análise da judicialização da saúde no Rio Grande do Sul e a temática da solidariedade entre os entes federados, o presente artigo revisitou os princípios da integralidade e da universalidade que orientam o SUS, bem como realizou uma análise do recente posicionamento do STF sobre a temática.

Tendo por referência dados coletados junto ao Sistema de Administração de 
Medicamentos da Secretaria de Saúde do Estado do Rio Grande do Sul, logrou-se comprovar que a judicialização sem observância da organização administrativa do SUS, acaba por vulnerar as políticas públicas, na medida em que não observa os princípios de organização e financiamento da saúde, razão pela qual o debate acerca da solidariedade entre os entes federados ganha ainda mais pertinência e atualidade.

Diante do exposto, conclui-se que a despeito do novo posicionamento do STF significar um avanço, no sentido de que a obrigação é solidária entre os entes, mas compete à autoridade judicial direcionar o cumprimento conforme as regras de repartição de competências, bem como o ressarcimento a quem suportou o ônus financeiro, muitas dúvidas de ordem processual ainda se impõe, sendo que a observância dos princípios de organização e financiamento do SUS são fundamentais para que se possa garantir a existência de um Sistema universal.

\section{Referências}

1. Ventura M, Simas, L, Pepe VLE, Schramm FR. Judicialização da saúde, acesso à justiça e a efetividade do direito à saúde. Disponível em: http://www.scielo.br/scielo.php? script=sci_arttext\&pid=S0103-73312010000100006\&lng=en [Acesso em 24 jun. 2019].

2. Oliveira MRM, Delduque MC, Sousa MF, Mendonça AVM. Judicialização da saúde: para onde caminham as produções científicas?. Saúde debate [Internet]. 2015 June; 39(105): 525-535. Disponível em: http://www.scielo.br/scielo.php?script=sci_arttext\&pid=S0103$11042015000200525 \&$ Ing =en [Acesso em 07 jul. 2019].

3. Leal MCH. A jurisdição constitucional entre judicialização e ativismo judicial. In: Leal MCH, Costa MMM (org.). Direitos Sociais e Políticas Públicas: desafios contemporâneos. t. 13. Santa Cruz do Sul: Edunisc, 2013, p. 217-246

4. Barboza EMQ, Kozicki K. Judicialização da política e controle judicial de políticas públicas. Disponível em: http://www.scielo.br/scielo.php?script=sci_arttext\&pid=\$1808-24322012000 100003 [Acesso em 25 ago. 2019].

5. Naundorf B, Carli P, Goulart B. O Estado do Rio Grande do Sul e os impactos da judicialização da saúde na gestão pública. In: Santos AO, Lopes LT. (Orgs.) Coletânea Direito à Saúde: dilemas do fenômeno da judicialização da saúde. Brasília: CONASS, 2018, p. 208-217.

6. Duarte LS, et. al. Regionalização da Saúde no Brasil: uma perspectiva de análise. Disponível em: http://www.scielo.br/scielo.php?script=sci_arttext\&pid=S0104-1290201 5000200472 [Acesso em 18 jun. 2019]. 
7. Rio Grande do Sul. Secretaria Estadual de Saúde. Sistema de Administração de Medicamentos da Secretaria de Saúde do Estado do Rio Grande do Sul. Dados Institucionais. [Acesso em 26 ago. 2019].

8. BRASIL. Lei 8.080 de 19 de setembro de 1980. Dispõe sobre as condições para a promoção, proteção e recuperação da saúde, a organização e o funcionamento dos serviços correspondentes e dá outras providências. Disponível em: http://www.planalto.gov.br/ ccivil_03/leis/l8080.htm [Acesso em 25 ago. 2019].

9. Rio Grande do Sul. Secretaria Estadual de Saúde. Fundo Estadual de Saúde. Dados Institucionais. [Acesso em 26 ago. 2019].

10. Rio Grande do Sul. Secretaria Estadual de Saúde. Coordenação de Política de Assistência Farmacêutica. Dados Institucionais. [Acesso em 26 ago. 2019].

11. Carli, Patrícia de. A judicialização da política e o protagonismo dos juízes nas decisões que envolvem o direito constitucional à saúde: reflexões acerca da jurisdição constitucional. Revista Eletrônica do Curso de Direito/UFSM, Santa Maria, RS, v.09, n.02, p. 284-304, 2014.

12. Brasil. Constituição da República Federativa do Brasil de 1988. Disponível em: http://www.planalto.gov.br/ccivil_03/constituicao/constituicao.htm [Acesso em 29 jun. 2019].

13. Ferraz OLM, Vieira FS. Direito à saúde, recursos escassos e equidade: os riscos da interpretação judicial dominante. Dados, Rio de Janeiro, v. 52, n. 1, p. 223-251. Mar, 2009. Disponível em: http://www.scielo.br/scielo.php?script=sci_arttext\&pid=S0011-52582009000 100007\&Ing=en\&nrm=iso [Acesso em 28 jun. 2019].

14. Biehl J, Socal MP, Amon JJ. The Judicialization of Health and the Quest for State Accountability: Evidence from 1,262 Lawsuits for Access to Medicines in Southern Brazil. Health Hum Rights. 2016 Jun;18(1):209-220.

15. Gebran Neto JP. Direito à saúde: direito constitucional à saúde e suas molduras jurídicas e fáticas. Disponível em: <http://www.conass.org.br/consensus/wp-content/uploads/2015/ 04/Artigo- direito-a- saude.pdf [Acesso em 07 abr. 2018].

16. Kalichman AO, Ayres JRCM. Integralidade e tecnologias de atenção à saúde: uma narrativa sobre contribuições conceituais à construção do princípio da integralidade no SUS. Disponível em: https://www.scielosp.org/article/csp/2016.v32n8/e00183415/ [Acesso em 29 jun. 2019].

17. Silva KB, Bezerra AFB, Tanaka OY. Direito à saúde e integralidade: uma discussão sobre os desafios e caminhos para a sua efetivação. Disponível em: http://www.scielo.br/pdf/icse/ 2012nahead/aop1812 [Acesso em 29 jun. 2019]. 
18. Cecílio LCO. As necessidades de saúde como conceito estruturante na luta pela integralidade e equidade na atenção em saúde. In: Pinheiro, R., Mattos RA. (Eds.). Os sentidos da integralidade na atenção e no cuidado à saúde. Rio de Janeiro: UERJIMSAbrasco, 2001, p.113-126.

19. Brandão C. Território e desenvolvimento: as múltiplas escalas entre o local e o global. 2. ed. Campinas: Editora da Unicamp, 2012.

20. BRASIL. Ministério da Saúde. Portaria de Consolidação no 03 , de 28 de setembro de 2017. Consolidação das Normas sobre as redes do Sistema Único de Saúde. Disponível em http://bvsms.saude.gov.br/bvs/saudelegis/gm/2017/prc0003_03_10_2017.html. [Acesso em 25 ago. 2019].

21. BRASIL. Decreto oㅜ 7.508, de 28 de junho de 2011. Regulamenta a Lei ํo 8.080 , de 19 de setembro de 1990, para dispor sobre a organização do Sistema Único de Saúde-SUS, o planejamento da saúde, a assistência à saúde e a articulação interfederativa, e dá outras providências. Disponível em: http://www.planalto.gov.br/ccivil_03/_ato20112014/2011/ decreto/D7508.htm. Acesso em 25 ago. 2019.

22. Mendes EV. As redes de atenção à saúde. Brasília: Organização Pan-Americana da Saúde, 2011.

23. Santos L. Região de saúde e suas redes de atenção: modelo organizativo-sistêmico do SUS. Disponível em: http://www.scielo.br/scielo.php?script=sci_arttext\&pid=S141381232017002401281 [Acesso em 29 jun. 2019].

24. Brasil. Lei 12.466 de 24 de agosto de 2011. Acrescenta arts. 14-A e 14-B à Lei no 8.080, de 19 de setembro de 1990, que "dispõe sobre as condições para a promoção, proteção e recuperação da saúde, a organização e o funcionamento dos serviços correspondentes e dá outras providências", para dispor sobre as comissões intergestores do Sistema Único de Saúde (SUS), o Conselho Nacional de Secretários de Saúde (Conass), o Conselho Nacional de Secretarias Municipais de Saúde (Conasems) e suas respectivas composições, e dar outras providências. Disponível em: http://www.planalto.gov.br/ccivil_03/_Ato20112014/2011/Lei/L12466.htm [Acesso em 29 jun. 2019].

25. Nascimento, VB. Interdependência e autonomia na gestão pública da saúde. Disponível em http://www.scielo.br/scielo.php?script=sci_arttext\&pid=S0102-64452001000100003 [Acesso em 25 ago. 2019].

26. Reis JR, Fontana E. O princípio da solidariedade e a hermenêutica filosófica na sustentabilidade dos direitos fundamentais sociais, diante dos argumentos do mínimo existencial e da reserva do possível. In: Reis JR, Leal RG. (Orgs.). Direitos sociais e políticas públicas: desafios contemporâneos. Tomo 10. Santa Cruz do Sul: Edunisc, 2010.

27. BRASIL. Lei 10.406, de 10 de janeiro de 2002. Institui o Código Civil Brasileiro. Disponível em http://www.planalto.gov.br/ccivil_03/leis/2002/10406.htm. [Acesso em 25 ago. 2019]. 
28. Santos L. O princípio da solidariedade no SUS. Disponível em: http://blogs.bvsalud.org/ds/2011/09/30/o-principio-da-solidariedade-no-sus/ [Acesso em 02 jul. 2019].

29. Brasil. Advocacia Geral da União. Audiência Pública no STF sobre o SUS. Disponível em: https://www.agu.gov.br/page/content/detail/id_conteudo/94850 [Acesso em 02 jul. 2019].

30. STF. Acompanhamento Processual. Disponível em: http://portal.stf.jus.br/processos/ detalhe .asp? incidente $=4678356$ [Acesso em 06 jul. 2019].

31. Morozowski AC, Oliveira LV. Da responsabilidade solidária na assistência à saúde. Disponível em https://www.migalhas.com.br/dePeso/16,MI305311,91041-Da+ Responsabilidade+solidaria+na+assistencia+a+saude+no+SUS [Acesso em 06 jul. 2019].

32. CNJ. Enunciados Aprovados II Jornada de Direito da Saúde. Disponível em https://www.cnj.jus.br/files/conteudo/destaques/arquivo/2015/05/96b5b10aec7e5954fcc197 8473e4cd80.pdf [Acesso em 26 ago. 2019].

33. Barros FPC, Delduque MC, Santos AO. O direito à saúde e a proposta de cobertura universal. Disponível em: https://www.conass.org.br/consensus/o-direito-saude-e-propostade-cobertura-universal/ [Acesso em 06 jun. 2019].

Como citar esse artigo:

De Carli P, Naundorf B. A aplicação do princípio da solidariedade na judicialização da saúde a partir dos princípios do SUS, da fixação de entendimento pelo STF e da trajetória do Rio Grande do Sul. Cadernos Ibero-Americanos de Direito Sanitário. 2019 jul./set.; 8(3): 112-130.

http://dx.doi.org/10.17566/ciads.v8i3.549 